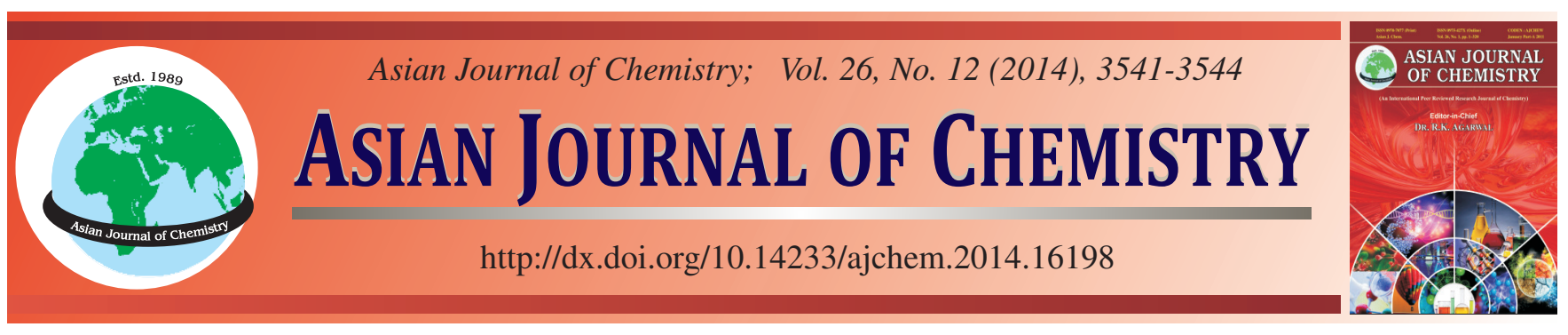

\title{
Molecularly Imprinted Solid-Phase Extraction of Tetracyclines Residue from Milk Using Internal-Surface Reversed-Phase Hybrid Composite Packing Materials
}

\author{
Yun-Kai Lv**, Jing-Qi Zhang, Zhi-Yong Guo, Wen-CAI WANG and BAO-Hui Li
}

College of Chemistry and Environmental Science, Hebei University, Key Laboratory of Analytical Science and Technology of Hebei Province, Baoding 071002, P.R. China

*Corresponding author: Fax: +86 312 5079628; Tel: +86 312 5079359; E-mail: lvyunkai@hbu.edu.com

\begin{abstract}
A novel internal-surface reversed-phase-molecularly imprinted polymer based on hybrid composite was developed for solid-phase extraction (SPE) of tetracyclines antibiotics from milk. The condition of loading, washing and eluting solvents in solid-phase extraction were investigated and evaluated by the recovery and retention of tetracyclines to obtain the optimum solid-phase extraction conditions. Under the optimal solid phase extraction conditions, three tetracyclines residues in milk were separated and detected by SPE-HPLC with better clean-up and enrichment. The mean recoveries of tetracycline antibiotics in milk were $85-106 \%$ for tetracycline, $76-88 \%$ for chlortetracycline and 90-94\% for doxycycline respectively, with relative standard deviations (RSDs) of 3.3-5.8\%. The limits of detection (LOD, S/N = 3) and the limits of quantitation (LOQ, S/N = 10) of the proposed method were 10.4 and $34.7 \mathrm{mg} \mathrm{kg}^{-1}$ for tetracycline, 13.8 and $46 \mathrm{mg} \mathrm{kg}^{-1}$ for chlortetracycline and 7.5 and $25.1 \mathrm{mg} \mathrm{kg}^{-1}$ for doxycycline, respectively.
\end{abstract}

Keywords: Molecularly imprinted polymers, Solid-phase extraction, Hybrid composite materials, Milk, Tetracyclines.

ᄂ - - - - - - - - - - - - - - - - - - - - - - - - - - -

\section{INTRODUCTION}

Tetracycline antibiotics (TCs) are commonly used antibiotics both for treatment of infectious diseases and as an additive to animal feeds ${ }^{1,2}$, because of their broad-spectrum antibacterial activity and cost effectiveness. However, relatively high levels of antibiotic residues in human foodstuffs can provoke allergic reactions in some hypersensitive individuals. In recent years, the abundant and in some cases improper use of tetracycline antibiotics has resulted in the presence of residues in edible animal tissues, which is toxic and dangerous for human health. Therefore, the development of novel molecularly imprinted polymers (MIPs) as sorbents for selective removal and separation of tetracycline antibiotics in foodstuff samples is of particular importance ${ }^{3-7}$.

Solid-phase extraction (SPE) is an attractive method for sample clean-up and preconcentration at trace level, owing to factors such as convenience, cost, time saving and simplicity ${ }^{4}$. For example, there is no sample manipulation between the preconcentration and the analysis steps, so loss of the analyte and the risk of contamination are reduced and the detection limits and the reproducibility improved ${ }^{8-11}$. Furthermore, the whole sample extract enters the analytical column, so the sample volume can be smaller, the consumption of organic solvents is lower and the potential for automation is improved ${ }^{12-15}$.
Recently, molecularly imprinted polymers have been recognized as useful materials for solid-phase extraction. Molecularly imprinted polymers are synthetic polymers with a predetermined selectivity for a given analyte, or a group of structurally related compounds ${ }^{16}$. Therefore, they have been increasingly exploited as selective sorbents in molecularly imprinted solid-phase extraction (MISPE) ${ }^{17-20}$. To improve further the selectivity and sample clean-up, a sample clean-up adsorbent of internal-surface reversed-phase (ISRP) materials was developed, such as organic polymer-based ISRP-MIPs ${ }^{21-24}$, silica surface imprinted internal-surface reversed-phase materials ${ }^{25}$. The internal-surface reversed-phase materials are special and selective extraction sorbent, large molecules such as proteins are eluted in the void volume without destructive accumulation because of restricted access to some surfaces, while allowing small molecules such as drugs and their metabolites to reach the hydrophobic, ion exchange, or affinity sites and be separated ${ }^{22}$.

In the present study, we developed a novel ISRP-MIP based on hybrid composite materials. We choose doxycycline as the template molecule, methacrylic acid as organic functional monomer, the styrene as common monomer, tetraethoxysilane as inorganic precursor and methacryloxy-propyltrimethoxysilane as the coupling agent, which was used to form the covalent bonding between organic and inorganic phases. 
A hydrophilic hybrid composite material has synthesized and applied to selective solid-phase extraction for efficient separation and clean-up of tetracycline antibiotic residues from milk samples.

\section{EXPERIMENTAL}

Tetracycline (TC), chlortetracycline (CTC) and doxycycline (DC) was purchased from Fluka (Buchs, Switzerland). Methacrylic acid (MAA) was purchased from Tianjin Chemical Reagent Research Institute (Tianjin, China) and was distilled. Styrene (St) and divinyl benzene (DVB) were purchased from Tianjin Chemical Reagent Research Institute (Tianjin, China) and was distilled. Methacryloxypropyltrimethoxysilane (KH570), $\gamma$-(2,3-epoxypropoxy)propytrimethoxysilane (KH560) and tetraethoxysilane (TEOS) were purchased from Nanjing Lianye Chemical Co., Ltd. (Shanghai, China). 2,2'Azo-bis(iso-butyronitrile) (AIBN) was purchased from Beijing Chemical Reagent Company (Beijing, China) and recrystallized from methanol. All the other chemicals were of the analytical or the HPLC grade and used without further disposal. Doubly deionized water was used throughout.

McIlvaine buffer solution: Mix $1000 \mathrm{~mL} 0.1 \mathrm{M}$ citric acid with $625 \mathrm{~mL} 0.2 \mathrm{M}$ disodium hydrogen phosphate ( $\mathrm{pH}$ adjusted to $4.0 \pm 0.05$ with $\mathrm{NaOH}$ or $\mathrm{HCl}$ as needed). $\mathrm{Na}_{2}$ EDTA-McIlvaine buffer solution $(0.1 \mathrm{M})$ : mix $60.5 \mathrm{~g}$ $\mathrm{Na}_{2}$ EDTA $2 \mathrm{H}_{2} \mathrm{O}$ into $1625 \mathrm{~mL}$ McIlvaine buffer.

Instrumentation and analytical conditions: HPLC analysis was performed in using a liquid chromatography system containing a LC-20AT pump, a SPD-20A UV-visible detector and RF-10AXL (Shimadzu, Japan). The analytes were separated in a Venusil XBP C18 column $(250 \times 4.6 \mathrm{~mm}, 5 \mathrm{~mm})$ from Bonna-Agela Technologies (Tianjin, China). HPLC analyses.

The mobile phase was methanol/acetonitrile/10 $\mathrm{mM}$ oxalic acid solution $(5: 25: 70, \mathrm{v} / \mathrm{v} / \mathrm{v})$ and the flow rate was 1.0 $\mathrm{mL} \min ^{-1}$ at $25{ }^{\circ} \mathrm{C}$. Aliquots of $10 \mathrm{~mL}$ were injected into the column and the chromatograms were recorded at $350 \mathrm{~nm}$.

Solid-phase extraction was performed in a 12-Ports Vacuum solid-phase extraction Manifold system (Beijing peaksharp analytical Instrument Co., Ltd. China) with vacuum control valve and poly (tetrafluoroethylene) cartridge adapters.

Preparation of the hydrophilic hybrid composite material: The polymer was prepared by precipitation polymerization using $0.151 \mathrm{~g}$ doxycycline as the template molecule, $0.22 \mathrm{~mL}$ methacrylic acid as functional monomer, $0.6 \mathrm{~mL}$ styrene as common monomer, $0.2 \mathrm{~mL}$ divinyl benzene as crosslinking agent and they were dissolved in $2.25 \mathrm{~mL}$ acetonitrile in a $50 \mathrm{~mL}$ round bottom flash. After prepolymerizing for $0.5 \mathrm{~h}$, $1.176 \mathrm{~mL} \mathrm{KH} 570$ and $0.1 \mathrm{~g}$ 2,2'-azo-bis(iso-butyronitrile) were added. The mixture was degassed in a sonicating water bath for $2 \mathrm{~min}$ and purged with nitrogen gas, the temperature was increased from room temperature to $60^{\circ} \mathrm{C}$ within $1 \mathrm{~h}$ and then kept at $60^{\circ} \mathrm{C}$ for $3 \mathrm{~h}$. Then, hydrolyzate solution of tetraethoxysilane $(2.95 \mathrm{~mL}$ of tetraethoxysilane was dissolved in $0.23 \mathrm{~mL}$ of $\mathrm{HCl}$ and $4.525 \mathrm{~mL}$ of ethanol and stirred for $1 \mathrm{~h}$ ) was added. The mixed solution was stirred at $60^{\circ} \mathrm{C}$ for $3 \mathrm{~h}$, after that the particles were filtered, dried at $60{ }^{\circ} \mathrm{C}$ for $24 \mathrm{~h}$. To ensure the complete removal of the templates, the materials were soxhlet extracted with a mixture of methanol/acetic acids (4:1, v/v) for $4 \mathrm{~h}$ and then washed with copious methanol. A further hydrophilic external layer was performed by $10 \%$ KH560 graft modification. The particles were finally filtered once again, washed with $100 \mathrm{~mL}$ toluene and $100 \mathrm{~mL}$ acetone. Particles were successively dried under vacuum over night at $40{ }^{\circ} \mathrm{C}$.

Molecularly imprinted solid-phase extraction procedure: Binding experiments were performed in water media. Briefly, $50 \mathrm{mg}$ dry polymer was packed into empty solid-phase extraction cartridges which is $5 \mathrm{~mm}$ in diameter, respectively and capped with fritted polyethylene disks at the top and bottom. Before use, the columns were preconditioned by successive washings with $\mathrm{MeOH}(3 \mathrm{~mL})$, water $(3 \mathrm{~mL})$, which was used to activate and equilibrium the columns. $5 \mathrm{~mL}$ of DCC solution or standard mixture solution in water $(\mathrm{pH} 6)$ was passed through the cartridges at a flow rate of $0.2 \mathrm{~mL}$ $\mathrm{min}^{-1}$. Then the cartridges were washed with $2 \mathrm{~mL}$ of methanol/ $\mathrm{H}_{2} \mathrm{O}(20: 80, \mathrm{v} / \mathrm{v})$. The doxycycline was eluted with $2 \mathrm{~mL}$ of methanol/acetic acid $(60: 40, \mathrm{v} / \mathrm{v})$. The collected solution was dried using a gentle stream of nitrogen. The residues were redissolved in the mobile phase and analyzed by HPLC-UV at $350 \mathrm{~nm}$. The cartridges were regenerated with $10 \mathrm{~mL}$ methanol/ acetic acid (80:20, v/v), dried and reused in subsequent studies.

Sample preparation: The milk samples were obtained from a local supermarket. $5 \mathrm{~g}$ of the milk sample was accurately weighed and placed in a $50 \mathrm{~mL}$ centrifuge tube, $20 \mathrm{~mL}$ Mcllvaine$\mathrm{Na}_{2}$ EDTA buffer solution was added to the sample and thoroughly mixed. Subsequently, ultrasound-assisted extractions were carried out at room temperature for $5 \mathrm{~min}$ and the samples were centrifuged at $10,000 \mathrm{rpm}$ for $10 \mathrm{~min}$. The residues of the milk were extracted twice. The supernatants of twice extraction were obtained and evaporated at $45^{\circ} \mathrm{C}$ by rotary evaporators. Then the residues were dissolved with water to $5 \mathrm{~mL}$ and filtration through a $0.45 \mathrm{~m}$ syringe filter, $5 \mathrm{~mL}$ of the filtrate was passed through the cartridges. The above-mentioned solidphase extraction procedure was used to separate and detect tetracycline antibiotics in milk. The samples were spiked with tetracycline antibiotics at concentration levels of $0.075,0.2$ and $0.5 \mathrm{mg} \mathrm{kg}^{-1}$.

\section{RESULTS AND DISCUSSION}

Several parameters must be optimized in MISPE experiments in order to maximize the selective recognition of the analytes. In order to optimize the selectivity of MISPE, conditioning, loading, washing and elution steps were evaluated and optimized. In the conditioning step, the binding sites must be activated by methanol solution. Thank to the hydrophilic groups bounded at the outer surface of particles, the polymer in favor of loading in aqueous solution. The optimization of $\mathrm{pH}$ value for adsorption medium plays a vital role in the adsorption studies. The adsorption test was performed by loading the cartridge with $5 \mathrm{~mL}$ of doxycycline standard water solution $\left(0.8 \mathrm{mg} \mathrm{mL}^{-1}\right)$ and the adsorption capacity after loading step was calculated by UV-visible spectrophotometer at $350 \mathrm{~nm}$. The effect of solution $\mathrm{pH}$ on the equilibrium adsorption capacity is shown in the Fig. 1 . As the $\mathrm{pH}=6$, the hydrophobic interaction and electrostatic attractions were benefited for the adsorption system. Therefore, water ( $\mathrm{pH}$ 6) was selected as loading solvent for further investigations. 


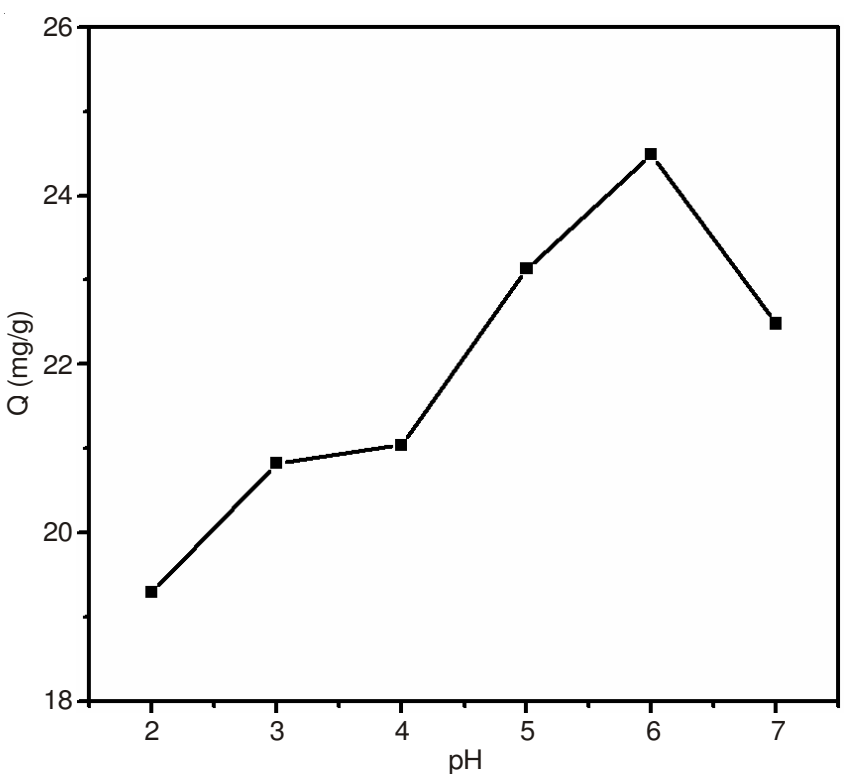

Fig. 1. Effect of the solution $\mathrm{pH}$ on the adsorption

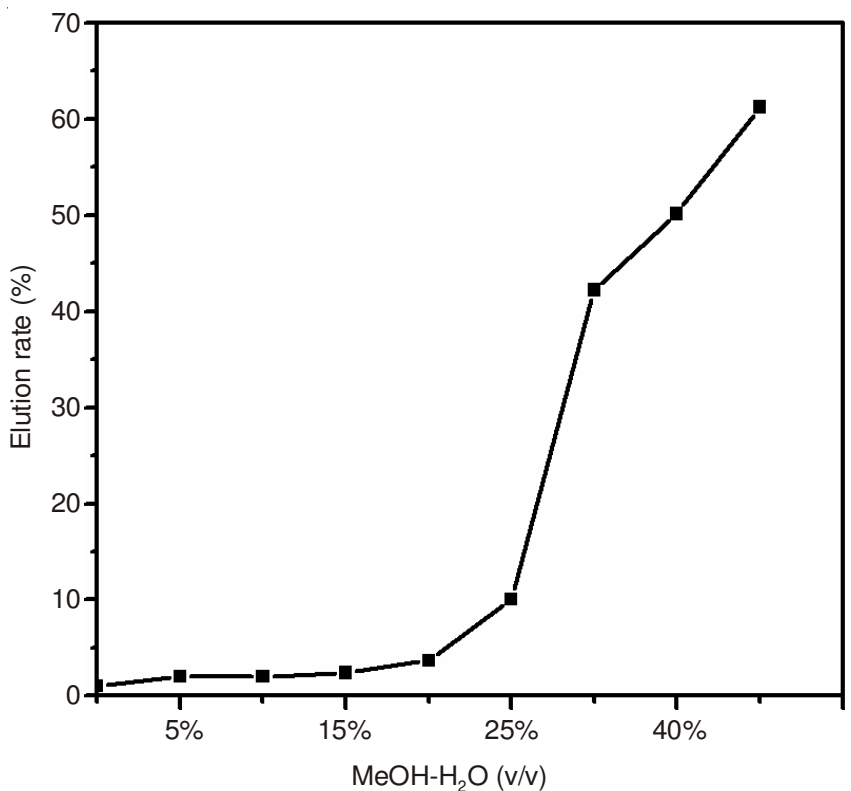

Fig. 2. Effect of different washing solution on the elution rate of doxycycline from the solid-phase extraction column

In order to enhance the selectivity of MIP for doxycycline and decrease the cross-reactivity, a washing step in the MISPE procedure was investigated using water, methanol and acetonitrile as potential washing solvents. The best results were obtained using $\mathrm{MeOH}$ and $\mathrm{H}_{2} \mathrm{O}$ as the washing solvent. The different proportions of methanol and water were also investigated. As seen in Fig. 2, when the increase of methanol content in washing solution, the doxycycline was eluted down gradually from the solid-phase extraction column. When the proportion of methanol and water as 20/80, eluting curve appeared inflection point and could obtain good clean-up effect, therefore, $2 \mathrm{~mL}$ of methanol/ $\mathrm{H}_{2} \mathrm{O}(20: 80$, v/v) was used as washing solution.

The eluting step was optimized based on the principle of elution that the analytes could be eluted completely by a small volume of strong solvent, while the impurities could not be eluted as much as possible. A series of methanol/acetic acid in

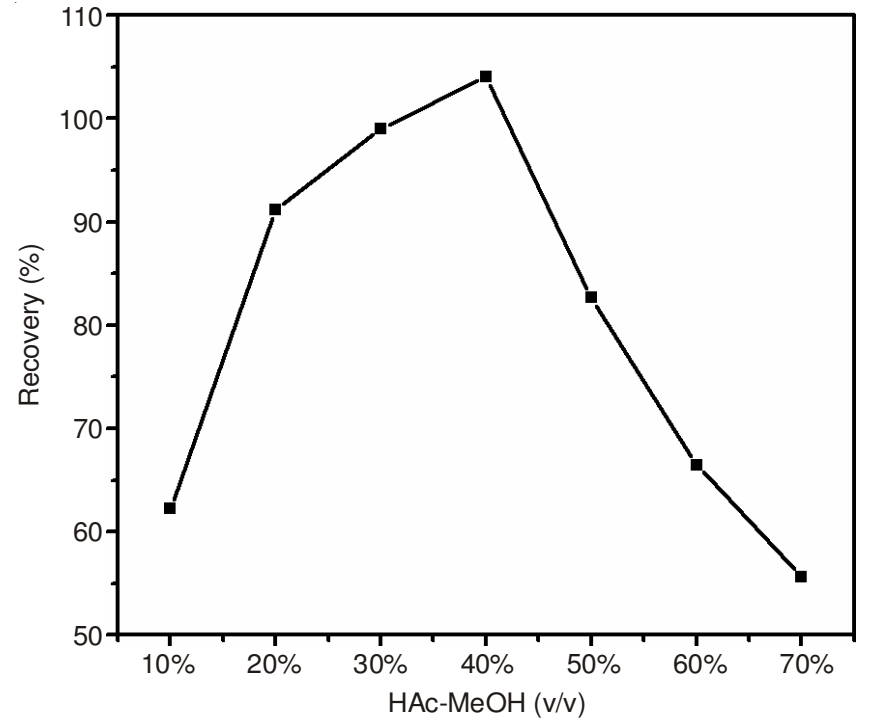

Fig. 3. Effect of different elution solution on the recoveries of doxycycline

different proportions were used to optimize the eluting conditions. In Fig. 3, the best recovery was obtained by using $2 \mathrm{~mL}$ of methanol/acetic acid (60:40, v/v) as eluting solution.

Analysis of milk samples: The milk samples were purchased from markets and analyzed by the SPE-HPLC. To demonstrate the feasibility of using solid-phase extraction to extract tetracycline antibiotics from the milk samples at MRL levels $(0.1$ $\left.\mathrm{mg} \mathrm{L}^{-1}\right), 5 \mathrm{~g}$ of the milk sample was treated using the protocol described in the experimental section. Compared with the spiked milk (Fig. 4a) and the spiked samples after solid-phase extraction (Fig. 4b), it showed the matrix interferences were eliminated. The mean recoveries of tetracycline antibiotics in milk evaluated by spiking samples with different concentrations $\left(0.075,0.2\right.$ and $\left.0.5 \mathrm{mg} \mathrm{kg}^{-1}\right)$ were $85-106 \%$ for tetracycline, 76-88\% for chlortetracycline and 90-94\% for doxycycline respectively, with relative standard deviations (RSDs) of 3.3-5.8\% (Table-1). The limits of detection (LOD, $\mathrm{S} / \mathrm{N}=3$ ) and the limits of quantitation (LOQ, $\mathrm{S} / \mathrm{N}=10$ ) of the milk samples were 10.4 and $34.7 \mu \mathrm{g} \mathrm{kg}^{-1}$ for tetracycline, 13.8 and $46 \mu \mathrm{g} \mathrm{kg}^{-1}$ for chlortetracycline and 7.5 and $25.1 \mu \mathrm{g} \mathrm{kg}^{-1}$ for doxycycline, respectively.

\section{Conclusion}

The internal-surface reversed-phase molecularly imprinted polymer-molecularly imprinted hybrid composite material was prepared by precipitation polymerization. It shows good purification effect, high selectivity and affinity. The results obtained the interactions between the polymer and the tetracycline antibiotics performed differently in various condition of loading, washing and eluting. The solid phase extraction technique was confirmed to be a powerful tool for efficient separation and fast enrichment of veterinary drug residues in milk samples.

\section{ACKNOWLEDGEMENTS}

This research was supported by the National Natural Science Foundation of China (No. 21275053) and the Natural Science Foundation of Hebei Province (No. B2011201081). 

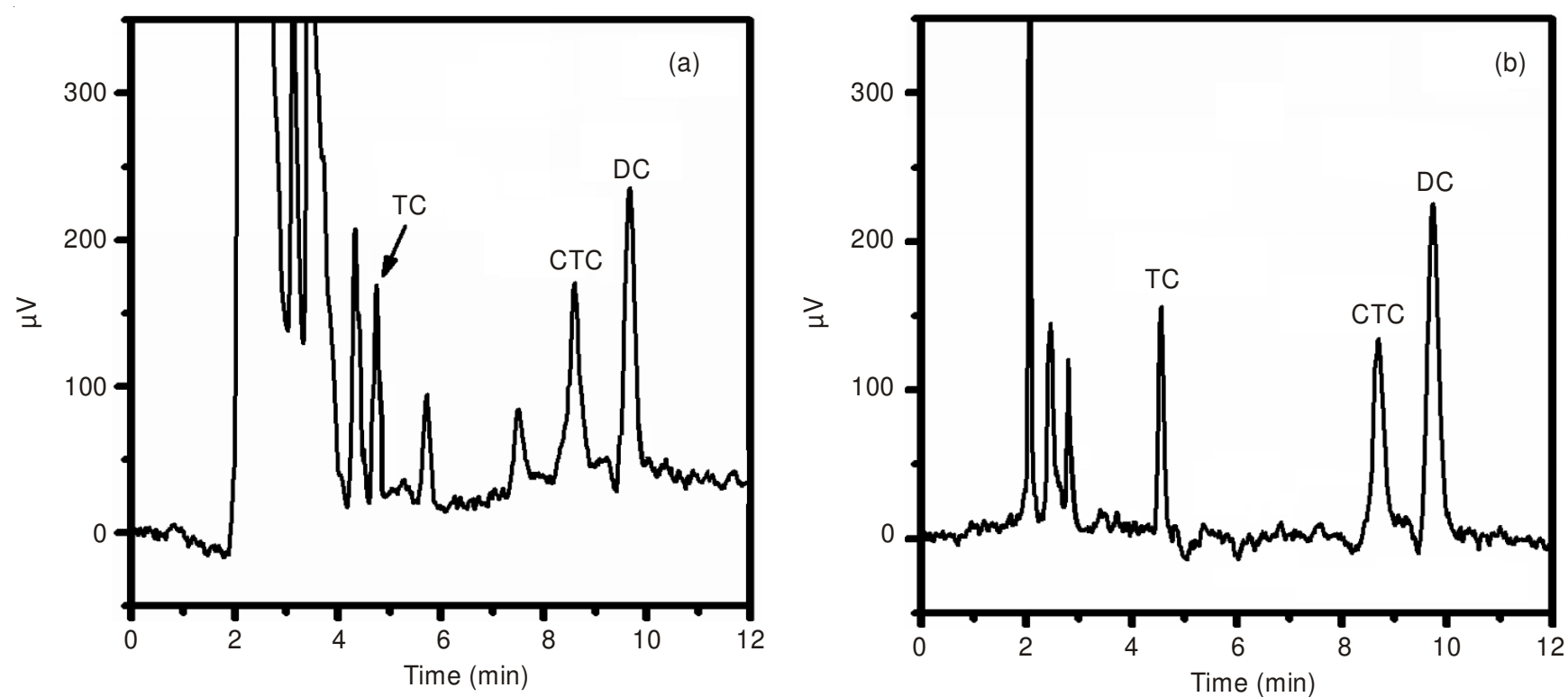

Fig. 4. Chromatograms obtained from the extraction of the tetracycline antibiotics from the milk samples. (a) spiked milk; (b) spiked milk with a clean-up of solid-phase extraction; mobile phase: methanol/acetonitrile/10 mM oxalic acid solution (5: 25: 70, v/v); flow rate: $1.0 \mathrm{~mL} / \mathrm{min}$; samples spiked concentration: $0.075 \mathrm{mg} / \mathrm{kg}$; injection volume: $10 \mu \mathrm{L}$

\begin{tabular}{|c|c|c|c|c|c|c|}
\hline \multicolumn{7}{|c|}{$\begin{array}{l}\text { TABLE-1 } \\
\text { AVERAGE RECOVERIES ( } R \text { ), RELATIVE STANDARD DEVIATIONS (RSDs, } \mathrm{n}=3 \text { ), LIMIT OF DETECTION } \\
\text { (LOD) AND LIMIT OF QUANTIFICATION (LOQ) OF TETRACYCLINE ANTIBIOTICs OBTAINED } \\
\text { AFTER SOLID-PHASE EXTRACTION OF SPIKED MILK SAMPLES }\end{array}$} \\
\hline Analyte & Spiked level $\left(\mathrm{mg} \mathrm{kg}^{-1}\right)$ & Detected $\left(\mathrm{mg} \mathrm{kg}^{-1}\right)$ & $\mathrm{R}(\%)$ & $\operatorname{RSD}(\%)$ & $\operatorname{LOD}^{\mathrm{a}}\left(\mu \mathrm{g} \mathrm{kg}^{-1}\right)$ & $\mathrm{LOQ}^{\mathrm{b}}\left(\mu \mathrm{g} \mathrm{kg}^{-1}\right)$ \\
\hline \multirow{3}{*}{ Tetracycline } & 0.075 & 0.071 & 95 & 3.8 & \multirow{3}{*}{10.4} & \multirow{3}{*}{34.7} \\
\hline & 0.2 & 0.17 & 85 & 3.3 & & \\
\hline & 0.5 & 0.53 & 106 & 5.7 & & \\
\hline \multirow{3}{*}{ Chlortetracycline } & 0.075 & 0.057 & 76 & 3.6 & \multirow{3}{*}{13.8} & \multirow{3}{*}{46.0} \\
\hline & 0.2 & 0.16 & 80 & 4.2 & & \\
\hline & 0.5 & 0.44 & 88 & 4.5 & & \\
\hline \multirow{3}{*}{ Doxycycline } & 0.075 & 0.068 & 91 & 5.5 & \multirow{3}{*}{7.5} & \multirow{3}{*}{25.1} \\
\hline & 0.2 & 0.18 & 90 & 5.8 & & \\
\hline & 0.5 & 0.47 & 94 & 3.4 & & \\
\hline
\end{tabular}

${ }^{a} \mathrm{LOD}$ calculated as three times the signal-to-noise ratio; ${ }^{\mathrm{b}} \mathrm{LOQ}$ calculated as 10 times the signal-to-noise ratio

\section{REFERENCES}

1. H. Oka, Y. Ito and H. Matsumoto, J. Chromatogr. A, 882, 109 (2000)

2. F. Trotta, C. Baggiani, M.P. Luda, E. Drioli and T. Massari, J. Membr. Sci., 254, 13 (2005).

3. T. Jing, Y. Wang, Q. Dai, H. Xia, J.W. Niu, Q.L. Hao, S.R. Mei and Y.K. Zhou, Biosens. Bioelectron., 25, 2218 (2010).

4. X.L. Sun, X.W. He, Y.K. Zhang and L.X. Chen, Talanta, 79, 926 (2009).

5. E. Caro, R.M. Marc'e, P.A.G. Cormack, D.C. Sherrington and F. Borrull, Anal. Chim. Acta, 552, 81 (2005).

6. S. Shariati, Y. Yamini and A. Esrafili, J. Chromatogr. B, 877, 393 (2009).

7. Y.K. Lv, L.M. Wang, L. Yang, C.X. Zhao and H.W. Sun, J. Chromatogr. A, 1227, 48 (2012).

8. T. Jing, X.D. Gao, P. Wang, Y. Wang, Y.F. Lin, X.Z. Hu, Q.L. Hao, Y.K. Zhou and S.R. Mei, Anal. Bioanal. Chem., 393, 2009 (2009).

9. H.Y. Yan and K.H. Row, Bull. Korean Chem. Soc., 29, 1173 (2008).

10. J.P. Li, F.Y. Jiang and X.P. Wei, Anal. Chem., 82, 6074 (2010).

11. H.Y. Yan, F.X. Qiao and K.H. Row, Anal. Chem., 79, 8242 (2007)

12. U. Koesukwiwat, S. Jayanta and N. Leepipatpiboon, J. Chromatogr. A, 1149, 102 (2007).

13. Y.K. Lv, C.L. Jia, X.H. Wang and L.W. Zhang, Asian J. Chem., 24, 3913 (2012)
14. G. Cirillo, M. Curcio, O.I. Parisi, F. Puoci, F. Iemma, U.G. Spizzirri, D. Restuccia and N. Picci, Food Chem., 125, 1058 (2011).

15. Y.K. Lv, L.M. Wang, M.G. Zhao, J.Q. Zhang and H.W. Sun, Asian J. Chem., 24, 3909 (2012)

16. K. Wybranska, W. Niemiec, K. Szczubialka, M. Nowakowska and Y. Morishima, Chem. Mater., 22, 5392 (2010).

17. R.J. Umpleby II, S.C. Baxter, M. Bode, J.K. Berch Jr., R.N. Shah and K.D. Shimizu, Anal. Chim. Acta, 435, 35 (2001).

18. X.W. Kan, Q. Zhao, D.L. Shao, Z.R. Geng, Z.L. Wang and J.J. Zhu, J. Phys. Chem. B, 114, 3999 (2010).

19. R.J. Umpleby, S.C. Baxter, Y.Z. Chen, R.N. Shah and K.D. Shimizu, Anal. Chem., 73, 4584 (2001).

20. R.B. Pernites, R.R. Ponnapati and R.C. Advincula, Macromolecules, 43, 9724 (2010).

21. F. Puoci, F. Iemma, G. Cirillo, M. Curcio, O.I. Parisi, U.G. Spizzirri and N. Picci, Eur Polym. J., 45, 1634 (2009).

22. J. Haginaka and H. Sanbe, Anal. Chem., 72, 5206 (2000).

23. J. Haginaka, H. Takehira, K. Hosoya and N. Tanaka, J. Chromatogr. A, 849, 331 (1999).

24. H. Sanbe and J. Haginaka, Analyst, 128, 593 (2003).

25. W. Xu, S. Su, P. Jiang, H. Wang, X. Dong and M. Zhang, J. Chromatogr. A, 1217, 7198 (2010). 